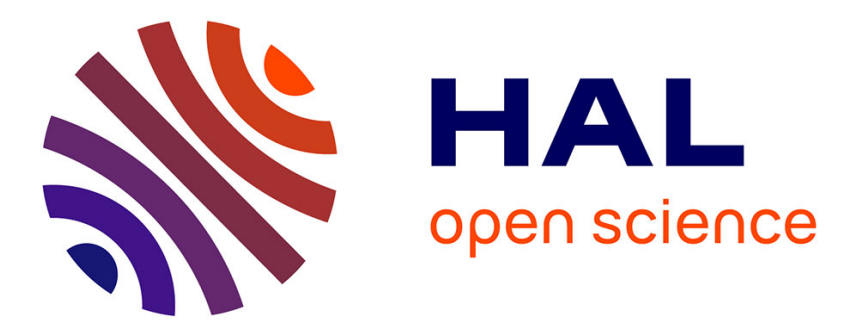

\title{
Sensitivity of Multi Carrier 2 Dimensional Spreading systems to carrier phase noise
}

\author{
Youssef Nasser, Mathieu Des Noes, Laurent Ros, Geneviève Jourdain
}

\section{To cite this version:}

Youssef Nasser, Mathieu Des Noes, Laurent Ros, Geneviève Jourdain. Sensitivity of Multi Carrier 2 Dimensional Spreading systems to carrier phase noise. IEEE International Workshop on Signal Processing Advances in Wireless communications (SPAWC'06), 2006, Cannes, France. hal-00077845

\section{HAL Id: hal-00077845 \\ https://hal.science/hal-00077845}

Submitted on 2 Jun 2006

HAL is a multi-disciplinary open access archive for the deposit and dissemination of scientific research documents, whether they are published or not. The documents may come from teaching and research institutions in France or abroad, or from public or private research centers.
L'archive ouverte pluridisciplinaire HAL, est destinée au dépôt et à la diffusion de documents scientifiques de niveau recherche, publiés ou non, émanant des établissements d'enseignement et de recherche français ou étrangers, des laboratoires publics ou privés. 


\title{
Sensitivity of Multi Carrier 2 Dimensional Spreading Systems to Carrier Phase Noise
}

\author{
${\text { Youssef } \operatorname{Nasser}^{(*)} \text {, Mathieu des Noes }}^{(*)}$, Laurent Ros ${ }^{(* *)}$ and Geneviève Jourdain ${ }^{(* *)}$ \\ ${ }^{(*)}$ youssef.nasser@cea.fr / mathieu.desnoes@cea.fr CEA-LETI, 38054 Grenoble cedex 09 France \\ ${ }^{(* *)}$ laurent.ros@lis.inpg.fr / genevieve.jourdain@lis.inpg.fr LIS, INPG, 46 Av. Felix Viallet, 38031 Grenoble France
}

\begin{abstract}
Phase noise is a topic of theoretical and practical interest in electronic circuits. Although progress has been made in the characterization of its description, there is still considerable gaps in its effect especially on the multi carrier spreading systems. In this paper, we investigate the impact of a local oscillator phase noise on the multi carrier 2 dimensional spreading systems known as OFDM-CDMA. The contribution of this paper is twofold. First, we use some properties of random matrix and free probability theory to give a simplified expression of the Signal to Interference and Noise Ratio SINR obtained after equalization and despreading. The latter is independent of the actual value of the spreading codes of different users and depends principally on the complex amplitudes of the estimated channel coefficients. Second, we use this expression to derive new weighting functions which are very interesting for the RF engineers when they design the frequency synthesizer. Simulation results are provided to discuss and validate our model.
\end{abstract}

Keywords: Multi carrier spreading systems, Large system analysis, Phase Noise, SINR.

\section{INTRODUCTION}

Recently, Orthogonal Frequency and Code Division Multiplexing (OFCDM) access technology has been investigated for the next generation of mobile communication systems [1][2]. It is a combination of Orthogonal Frequency Division Multiplexing (OFDM) and Code Division Multiple Access (CDMA). To achieve high spectrum efficiency, these systems will implement a large number of sub-carriers and, as a consequence, will be highly sensitive to phase noise [3]. The phase noise creates two effects: the Common Phase Error CPE and the Inter Carrier Interference ICI. CPE alters equivalently the different carriers by causing sub carrier phase rotation while ICI introduces interferences to any sub carrier from all other sub carriers. In the literature, the phase noise effect was been presented in some papers for OFDM [3][4][5] and MCCDMA systems [6]. Nevertheless, the analytical results of [6] have assumed independent identically distributed iid spreading codes i.e. the orthogonality between codes is not accounted for. Moreover, their results are only suitable for Additive White Gaussian Noise AWGN.

This paper presents the degradation introduced by a carrier phase noise on the performance of a downlink 2 dimensional spreading OFDM-CDMA system [1][2]. It extends to a 2 Dimensional OFDM-CDMA context the works of [7] which was done for a MC-CDMA system. It is also based on our previous works done for different synchronization errors in OFDM-CDMA systems [8][9][10]. Using some properties of random matrix theory and free probability theory, a new analytical expression of the SINR has been developed. This SINR formula is independent of the actual values of the spreading codes while taking into account their orthogonality. It depends only on the complex amplitudes of the channel coefficients, the average transmitted power of the interfering users and the affected power of the desired user. It has been validated thanks to link level simulation based on accurate phase noise models [11]. Moreover, the SINR expression allows us to derive SINR degradations in different scenarios and to derive new weighting functions, such as proposed by Stott [4] for OFDM system and [7] for MC-CDMA systems. These functions will give a better understanding of the phase noise effect on the system performance.

This article is organized as follows. Section 2 describes the system model for OFDM-CDMA system including transmitter, channel model with carrier phase noise and receiver. Section 3 describes the phase noise model. Section 4 gives an asymptotical expression of the estimated SINR. In section 5, we derive new weighting functions for OFDMCDMA systems while section 6 presents system performance. Eventually, conclusions are drawn in section 7.

\section{SYSTEM MODEL}

In this section, the generalized framework describing an OFDM-CDMA system is presented. Figure 1 shows a 2

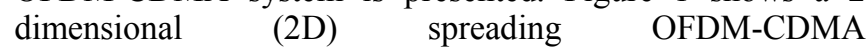
transmitter/receiver chain for a downlink communication with $\mathrm{N}_{\mathrm{u}}$ users [1]. For each user, each symbol is first spread by a Walsh-Hadamard WH sequence of $\mathrm{N}_{c}$ chips, and scrambled by a portion of $\mathrm{N}_{\mathrm{c}}$ chips of the cell specific long pseudo random sequence. This scrambling code is used to minimize the multi-cell interference. The resulting chips are then allocated on the time/frequency grid as shown on Figure 2. Assuming an IFFT of $\mathrm{N}$ sub carriers, each user transmits $\mathrm{S}=\mathrm{N} / \mathrm{N}_{\mathrm{F}}$ data symbols $\mathrm{a}_{\mathrm{m}}[\mathrm{s}]$ of the $\mathrm{m}^{\text {th }}$ user on the $\mathrm{i}^{\text {th }}$ OFDMCDMA block composed of $\mathrm{N}_{\mathrm{T}}$ OFDM symbols. $\mathrm{N}_{\mathrm{F}}$ and $\mathrm{N}_{\mathrm{T}}$ are respectively the frequency and time domain spreading factors. The system is thus a general case of the MC-CDMA [13] and MC-DS-CDMA [14] systems. The scheme is identical for other users using one specific WH sequence by user, with $\mathrm{N}_{\mathrm{u}} \leq \mathrm{N}_{\mathrm{c}}$. For simplicity and without loss of generality, we will drop the index $i$ in the sequel.

Eventually, the signal at the IFFT input is: 


$$
\begin{aligned}
& b_{q}\left[s N_{F}+n\right]=\sum_{m=0}^{N_{u}-1} \sqrt{P_{m}} a_{m}[s] C_{m, s}\left[n N_{T}+q\right] \\
& \quad q=0, \ldots, N_{T}-1 ; s=0, \ldots, S-1, n=0, \ldots, N_{F}-1
\end{aligned}
$$

$\mathrm{s}$ is the index referring to the sub band used for the transmission of the symbol $a_{m}[s]$ of the $m^{\text {th }}$ user. $P_{m}$ is its transmit power which is identical in all sub-bands, $\mathrm{C}_{\mathrm{m}, \mathrm{s}}$ represents its spreading sequence (chip by chip multiplication of the user assigned $\mathrm{WH}$ sequence and the cell specific scrambling code).

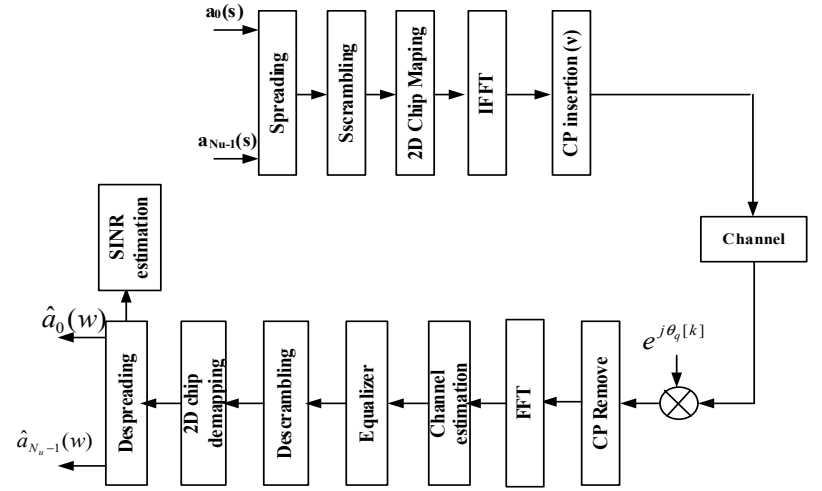

Figure 1: OFDM-CDMA Transceiver.

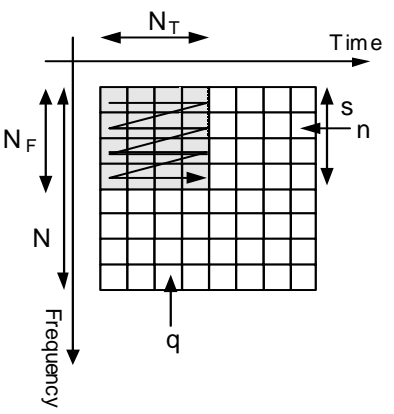

Figure 2: Time Frequency grid

At the output of the IFFT, a cyclic prefix CP of $v$ samples is inserted to discard the inter symbol interference. The signal is then converted to Radio Frequency by the RF unit. It is then convoluted by the multipath propagation channel which is modelled by its base band function as a FIR filter $_{h_{q}}(z)=\sum_{k=0}^{W-1} g_{q}[k] z^{-k}$ where $\mathrm{g}_{\mathrm{q}}[\mathrm{k}]$ is the Channel Impulse Response (CIR) and W is the delay spread which is assumed less than the cyclic prefix $(\mathrm{W} \leq v)$. The signal at the channel output is then corrupted by an AWGN with variance $\sigma^{2}$.

At the receiving side, the signal is down converted by the receiver RF unit. The phase noise is the phase error between the carrier used for up conversion at the transmitter and the carrier used for down conversion at the receiver. It can be represented by a simple random phase rotation of the samples at the input of the CP remove module. Therefore, the received samples can be written as

$$
\begin{gathered}
r_{q}[k]=\frac{e^{j \theta_{q}[k]}}{N} \sum_{s=0}^{S-1} \sum_{n=0}^{N_{F}-1} b_{q}\left[s N_{F}+n\right] h_{q}\left[s N_{F}+n\right] e^{-j 2 \pi \frac{s N_{F}+n}{N} k}+n_{q}[k] \\
\text { with } k=0, \ldots, N-1
\end{gathered}
$$

Where $h_{q}\left[s N_{F}+n\right]=\left.h_{q}(z)\right|_{z=e^{j 2 \pi \frac{\left(s N_{F}+n\right)}{N}}}$ is the FFT of the CIR $\mathrm{g}_{\mathrm{q}}[\mathrm{k}]$ on the sub carrier $\mathrm{n}$ of $\mathrm{s}^{\text {th }}$ sub band, $\mathrm{n}_{\mathrm{q}}[\mathrm{k}]$ is the AWGN and $\theta_{\mathrm{q}}[\mathrm{k}]$ is the phase noise.

After the FFT operation, the value of $\left(\mathrm{wN}_{\mathrm{F}}+\mathrm{p}\right)^{\text {th }}$ sub-carrier of the $\mathrm{q}^{\text {th }}$ OFDM symbol of an OFDM-CDMA block is:

$$
R_{q}\left[w N_{F}+p\right]=\sum_{s=0}^{S-1} \sum_{n=0}^{N_{F}-1} b_{q}\left[s N_{F}+n\right] \phi(w, s, p, n, q)+N_{q}\left[w N_{F}+p\right]
$$

$\mathrm{w}$ is the desired sub-band index $(\mathrm{w}=0, \ldots, \mathrm{S}-1)$ and $\mathrm{p}$ is the index of a sub-carrier in the $\mathrm{w}^{\text {th }}$ sub-band $\left(\mathrm{p}=0, \ldots, \mathrm{N}_{\mathrm{F}}-1\right)$. $\phi(\mathrm{w}, \mathrm{s}, \mathrm{p}, \mathrm{n}, \mathrm{q})$ is the "frequency side-to-side" equivalent channel transfer function (IFFT-channel-FFT) including the effect of the phase noise. It is given by

$\phi(w, s, p, n, q)=\frac{h_{q}\left[s N_{F}+n\right]}{N} \sum_{u=0}^{N-1} \exp \left(-j 2 \pi \frac{(w-s) N_{F}+(p-n)}{N} u\right) \exp \left(j \theta_{q}[u]\right)$

Equation (4) shows that for $\mathrm{w}=\mathrm{S}$ and $\mathrm{p}=\mathrm{n}$ (interesting $\left(\mathrm{wN}_{\mathrm{F}}+\mathrm{p}\right)^{\text {th }}$ sub-carrier $), \phi(\mathrm{w}, \mathrm{w}, \mathrm{p}, \mathrm{p}, \mathrm{q})$ characterizes the CPE altering equivalently all sub carriers.

Without loss of generality, we assume that one is interested by the symbols of user 0 . In order to write the received signal with a matrix-vector notation, the following matrices are defined: $\mathrm{P}=\operatorname{diag}\left(\mathrm{P}_{0}, \ldots, \mathrm{P}_{\mathrm{Nu}-1}\right)$ is the $\mathrm{N}_{\mathrm{u}} \mathrm{xN}_{\mathrm{u}}$ diagonal matrix which entries are the powers allocated to each user, $\mathrm{Q}=\operatorname{diag}\left(\mathrm{P}_{1}, \ldots, \mathrm{P}_{\mathrm{Nu}-1}\right)$ is the $\left(\mathrm{N}_{\mathrm{u}}-1\right) \times\left(\mathrm{N}_{\mathrm{u}}-1\right)$ diagonal matrix containing the powers of the interfering users, $\mathrm{C}[\mathrm{s}]=\left(\mathrm{C}_{0}[\mathrm{~s}], \mathrm{C}_{1}[\mathrm{~s}], \ldots, \mathrm{C}_{\mathrm{Nu}-1}[\mathrm{~s}]\right)$ is the $\mathrm{N}_{\mathrm{c}} \mathrm{xN}_{\mathrm{u}}$ matrix containing all the spreading codes used in the $\mathrm{s}^{\text {th }}$ sub-band and $\mathrm{U}[\mathrm{s}]=\left(\mathrm{C}_{1}[\mathrm{~s}], \ldots, \mathrm{C}_{\mathrm{Nu}-1}[\mathrm{~s}]\right)$ is the $\mathrm{N}_{\mathrm{c}} \mathrm{x}\left(\mathrm{N}_{\mathrm{u}}-1\right)$ matrix containing the codes of the interfering users in the $s^{\text {th }}$ subband. Both matrices $\mathrm{C}[\mathrm{s}]$ and $\mathrm{U}[\mathrm{s}]$ depend on sub-band index $\mathrm{s}$ because of the long scrambling code. We also define the vectors $a[s]=\left(a_{0}[s], \ldots, a_{N_{u}-1}[s]\right)^{T}$ and $\widetilde{a}[s]=\left(a_{1}[s], \ldots, a_{N_{u}-1}[s]\right)^{T}$ corresponding to the symbols of all users and interfering users respectively transmitted in the $s^{\text {th }}$ sub-band. The estimated symbol of the reference user on the sub-band $\mathrm{w}$ after equalization and despreading is then:

$$
\begin{aligned}
& \hat{a}_{0}[w]=I_{0}+I_{1}+I_{2}+I_{3}+I_{4} \\
& I_{0}=\sqrt{P_{0}} C_{0}^{H}[w] Z[w] H[w, w] C_{0}[w] a_{0}[w] \\
& I_{1}=C_{0}^{H}[w] Z[w] H[w, w] U[w] Q[s] \widetilde{a}[w] \\
& I_{2}=\sum_{\substack{s=0 \\
s \neq 1}}^{s=1} C_{0}^{H}[w] Z[w] H[w, s] C[s] P[s] a[s] \\
& I_{3}=C_{0}^{H}[w] Z[w] N[w]
\end{aligned}
$$

$\mathrm{I}_{0}$ represents the useful signal, $\mathrm{I}_{1}$ the Multiple Access Interference (MAI) of the same sub band $\mathrm{w}, \mathrm{I}_{2}$ the interference generated by all users from other sub bands (Inter Band Interference IBI) and $\mathrm{I}_{3}$ the noise. $\mathrm{H}[\mathrm{w}, \mathrm{s}]$ is a $\mathrm{N}_{\mathrm{c}} \times \mathrm{N}_{\mathrm{c}}$ matrix which components represent the frequency channel coefficients depending on the phase noise.

$$
\begin{gathered}
H_{p, n}[w, s]=\left(\begin{array}{cccc}
A[0,0] & \cdots & \ldots & A\left[0, N_{F}-1\right] \\
A[1,0] & \ddots & & A\left[1, N_{F}-1\right] \\
\vdots & \vdots & A[p, n] & \vdots \\
A\left[N_{F}-1,0\right] & \cdots & \cdots & A\left[N_{F}-1, N_{F}-1\right]
\end{array}\right) \\
A[p, n]=\left(\begin{array}{cccc}
\phi(w, s, p, n, 0) & 0 & \cdots & 0 \\
0 & \ddots & \ddots & \vdots \\
\vdots & \ddots & \ddots & 0 \\
0 & \cdots & 0 & \phi\left(w, s, p, n, N_{T}-1\right)
\end{array}\right)
\end{gathered}
$$

$\mathrm{Z}[\mathrm{w}]$ is a $\mathrm{N}_{\mathrm{c}} \times \mathrm{N}_{\mathrm{c}}$ diagonal matrix which equalizes the diagonal elements of $\mathrm{H}[\mathrm{w}, \mathrm{s}]$.

\section{PHASE NOISE MODEL}

The phase noise $\theta(\mathrm{t})$ generated at the carrier oscillator can be described as a continuous Brownian motion process with a zero mean and variance $2 \mathrm{Dt}$. D is the phase noise line-width commonly known as the diffusion factor [12]. It characterizes the 3-dB bandwidth of its Lorentzian Power Spectral Density 
function [3]. Such noise has independent Gaussian increments which can be represented as a finite-power Wiener phase whose spectrum decreases with the inverse of the square of the frequency. Its PSD is

$$
S_{\theta}(f)=\frac{2 D}{D^{2}+(2 \pi f)^{2}}
$$

The phase noise $\theta_{\mathrm{q}}[\mathrm{k}]$ given in the previous equations can be obtained from $\left.\theta(\mathrm{t})\right|_{\mathrm{t}=[\mathrm{q}(\mathrm{N}+\mathrm{v})+\mathrm{k}] \mathrm{Ts}}\left(\mathrm{T}_{\mathrm{s}}\right.$ is the sampling period) with the iterative function

$$
\theta_{q}[k+1]=\theta_{q}[k]+\Gamma_{q}[k]
$$

Where $\Gamma_{\mathrm{q}}[\mathrm{k}]$ is a zero mean i.i.d gaussian random variable with variance $2 \mathrm{DT}_{\mathrm{s}}$. When the oscillator is integrated in a PLL, its Wiener phase noise is filtered by the PLL closed loop filter $\mathrm{F}(\mathrm{z})$. Therefore, the filtered phase noise PSD is

$$
S(f)=S_{\theta}(f)\left|F\left(e^{j 2 \pi f}\right)\right|^{2}
$$

In this case (the free-running oscillator is suited by a Phase Locked Loop synthesizer), the phase noise is assumed as the so-called small-angle approximation. Moreover, for smallangle assumption, (4) yields:

$\phi(w, s, p, n, q)=h_{q}\left[s N_{F}+n\right]\left(\delta(w, s)(p, n)+\frac{j}{N} \sum_{u=0}^{N-1} \theta_{q}[u] \exp \left(-j 2 \pi \frac{(w-s) N_{F}+(p-n)}{N} u\right)\right)$

Where $\delta(w, s)(p, n)=1$ if $w=s$ and $p=n$ and zero elsewhere. The assumption of small angle is due to the reduction of the variance of the phase noise by introducing it in a PLL filter.

In this paper, the PLL synthesizer is modelled by a second order high pass filter. Its coefficients are synthesized according to the cut-off frequency and the resonance parameter of the filter. It is given

$$
F(z)=\frac{b_{0}+b_{1} z^{-1}+b_{2} z^{-2}}{a_{0}+a_{1} z^{-1}+a_{2} z^{-2}}
$$

\section{SINR EVALUATION}

The data symbols are assumed i.i.d. having zero mean and unit variance. The SINR for every sub band is deduced from (5) by calculating the expectation values over the random data symbols of $\mathrm{I}_{0}, \mathrm{I}_{1}, \mathrm{I}_{2}$ and $\mathrm{I}_{3}$. It is given by

$$
\operatorname{SINR}=\frac{E\left|I_{0}\right|^{2}}{E\left|I_{1}\right|^{2}+E\left|I_{2}\right|^{2}+E\left|I_{3}\right|^{2}}
$$

The expectations values in (11) are given by

$$
\begin{aligned}
& E\left|I_{0}\right|^{2}=P_{0}\left|C_{0}^{H}[w] Z[w] H[w, w] C_{0}[w]\right|^{2} \\
& E\left|I_{1}\right|^{2}=C_{0}^{H}[w] Z[w] H[w, w] U[w] Q U^{H}[w] H[w, w]^{H} Z[w]^{H} C_{0}^{H}[w] \\
& E\left|I_{2}\right|^{2}=\sum_{\substack{s=0 \\
s \neq}}^{S-1} C_{0}^{H}[w] Z[w] H[w, s] C[s] P C^{H}[s] H[w, s]^{H} Z[w]^{H} C_{0}^{H}[w] \\
& E\left|I_{3}\right|^{2}=\frac{\sigma^{2}}{N_{c}} \operatorname{tr}\left(Z[w] Z[w]^{H}\right)
\end{aligned}
$$

These expressions show that the SINR depends on a complex way of the actual spreading codes. (12) can not be used practically due to its complexity. Thus, we define some properties of random matrix and free probability theories as in our previous works [8][9][10] to show that the dependence of the SINR on the spreading codes was vanishing in the asymptotic regime $\left(\mathrm{N}_{\mathrm{c}}\right.$ and $\mathrm{N}_{\mathrm{u}} \rightarrow \infty$ while the ratio $\alpha=\mathrm{N}_{\mathrm{u}} / \mathrm{N}_{\mathrm{c}}$ is kept constant).

Property 1: if $A$ is a $\mathrm{N}_{\mathrm{c}} \times \mathrm{N}_{\mathrm{c}}$ uniformly bounded deterministic matrix and
$C_{m}=\frac{1}{\sqrt{N_{c}}}\left(c_{m}(0), \ldots ., c_{m}\left(N_{c}-1\right)\right)$ where $\mathrm{c}_{\mathrm{m}}(1)$ are iid complex random variables with zero mean, unit variance and finite eighth order moment, then [18]:

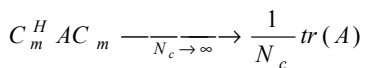

This property is used to evaluate $\mathrm{E}\left|\mathrm{I}_{0}\right|^{2}, \mathrm{E}\left|\mathrm{I}_{1}\right|^{2}$, and $\mathrm{E}\left|\mathrm{I}_{2}\right|^{2}$.

Property 2: Let $\mathrm{C}$ a Haar distributed unitary matrix of size $\mathrm{N}_{\mathrm{c}} \times \mathrm{N}_{\mathrm{u}}$ [17]. C can be decomposed into a vector $\mathrm{C}_{0}$ of size $\mathrm{N}_{\mathrm{c}}$ and a matrix $U$ of size $\mathrm{N}_{\mathrm{c}} \times \mathrm{N}_{\mathrm{u}-1}$. So, $\mathrm{C}$ can be written as $\mathrm{C}=\left(\mathrm{C}_{0}, \mathrm{U}\right)$. Given these hypothesises, it is proven in [16] that:

$$
U Q U^{H}-\overline{N_{c}} \rightarrow \infty \rightarrow \alpha \bar{P}\left(I-C_{0} C_{0}^{H}\right)
$$

$\alpha=\mathrm{N}_{\mathrm{u}} / \mathrm{N}_{\mathrm{c}}$ is the system load and $\bar{P}=\frac{1}{N_{u}-1} \sum_{m=1}^{N_{u}-1} P_{m}$ is the average power of the interfering users. The Haar distributed assumption is only technical and will not change in the total result. The simulation results obtained in [16] with a WalshHadamard spreading matrix match well with the theoretical model. This lemma is used to evaluate $\mathrm{E}\left|\mathrm{I}_{1}\right|^{2}$ and $\mathrm{E}\left|\mathrm{I}_{2}\right|^{2}$.

Property 3: If $\mathrm{C}$ is generated from a $\mathrm{N}_{\mathrm{c}} \times \mathrm{N}_{\mathrm{c}}$ Haar unitary random matrix then matrices $\mathrm{C}[\mathrm{s}] \mathrm{QC}^{\mathrm{H}}[\mathrm{s}]$ and $\mathrm{Z}[\mathrm{w}]^{\mathrm{H}} \mathrm{H}[\mathrm{w}, \mathrm{s}]^{\mathrm{H}} \mathrm{H}[\mathrm{w}, \mathrm{s}] \mathrm{Z}[\mathrm{w}]$ are asymptotically free almost everywhere [19]. Then, one can conclude:

$$
\begin{aligned}
& \frac{1}{N_{c}} \operatorname{tr}\left(Z[w] H[w, s] C[s] P C^{H}[s] H[w, s]^{H} Z[w]^{H}\right) \underset{N_{c} \rightarrow \infty}{\longrightarrow} \\
& \frac{1}{N_{c}} \operatorname{tr}\left(Z[w] H[w, s] H[w, s]^{H} Z[w]^{H}\right) \times \frac{1}{N_{c}} \operatorname{tr}\left(C[s] P C^{H}[s]\right)
\end{aligned}
$$

This lemma is used to evaluate $\mathrm{E}\left|\mathrm{I}_{2}\right|^{2}$. With these assumptions, (12) yields for a given phase noise value [9][10]:

$$
\begin{aligned}
E\left|I_{0}\right|^{2} & =P_{0}\left|\frac{1}{N_{c}} \operatorname{tr}(Z[w] H[w, w])\right|^{2} \\
E\left|I_{1}\right|^{2} & =\alpha \bar{P}\left(\frac{1}{N_{c}} \operatorname{tr}\left(Z[w] H[w, w] H[w, w]^{H} Z[w]^{H}\right)-\left|\frac{1}{N_{c}} \operatorname{tr}(Z[w] H[w, w])\right|^{2}\right) \\
E\left|I_{2}\right|^{2} & =\frac{\alpha \bar{P}}{N_{c}} \sum_{\substack{s=0 \\
s \neq 1}}^{S-1} \operatorname{tr}\left(Z[w] H[w, s] H[w, s]^{H} Z[w]^{H}\right) \\
E\left|I_{3}\right|^{2} & =\frac{\sigma^{2}}{N_{c}} \operatorname{tr}\left(Z[w] Z[w]^{H}\right)
\end{aligned}
$$

We will now exploit (16) to expand an analytical expression of the asymptotical SINR. First, we assume that the receiver uses a MMSE equalizer which coefficients are given by:

$$
z_{q}\left[w N_{F}+p\right]=\frac{\phi^{*}(w, w, p, p, q)}{|\phi(w, w, p, p, q)|^{2}+\gamma}
$$

$\gamma$ is the inverse of the SNR per sub-band : $\gamma=\alpha \bar{P}[w] / \sigma^{2}$.

Notice that, according to equation (4), the coefficient $\phi(w, w, p, p, q)$ resumes to the time average during one OFDM symbol of the equivalent channel. Expanding the expressions of (16) and computing the expectations over the phase noise realizations, we use Parseval's identity to verify that (16) yields 


$$
\begin{aligned}
& \left.E I_{0}\right|^{2}=P_{0}\left|\frac{1}{N_{c}} \sum_{p=0}^{N_{F}-1 N_{T-1}} \sum_{q=0} \frac{\mid h_{q}\left[w N_{F}+\left.p\right|^{2}\right.}{\mid h_{q}\left[w N_{F}+p||^{2}+\gamma\right.}\right|^{2} \\
& I[w]=\frac{\overline{\alpha P}}{N_{c}} \sum_{p=0}^{N_{F}-1 N_{T}-1} \frac{\mid h_{q=0}\left[w N_{F}+\left.p\right|^{4}\right.}{\mid h_{q}\left[w N_{F}+\left.p\right|^{2}+\left.\gamma\right|^{2}\right.}-\overline{\alpha P} \mid \frac{1}{\mid N_{c}} \sum_{p=0}^{N_{F}-1} \sum_{q=0} \frac{\mid N_{T}-1}{\mid h_{q}\left[w N_{F}+\left.p\right|^{2}+\gamma \mid\right.} \\
& +\frac{\sigma^{2}}{N_{c}} \sum_{p=0}^{N_{F}-1} \sum_{\varphi=0} \frac{\mid h_{q}\left[w N_{F}+\left.p\right|^{2}\right.}{|| h_{q}\left[w N_{F}+\left.p\right|^{2}+\eta^{2}\right.}
\end{aligned}
$$

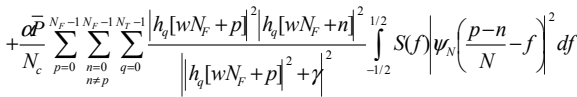

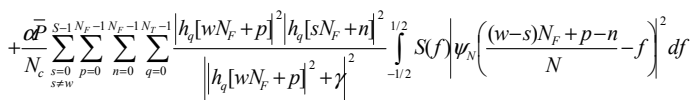

Where $\mathrm{I}[\mathrm{w}]=\mathrm{E}\left|\mathrm{I}_{1}\right|^{2}+\mathrm{E}\left|\mathrm{I}_{2}\right|^{2}+\mathrm{E}\left|\mathrm{I}_{3}\right|^{2}$ is the total interference power and $\Psi_{\mathrm{N}}$ is the function defined by $\psi_{N}(x)=\frac{1}{N} \frac{\sin (\pi N x)}{\sin (\pi x)}$.

\section{WEIGHTING FUNCTIONS}

Equation (17) shows that the interference power is composed of three expressions which are independent on the phase noise and two others which are dependent on the phase noise. A better understanding of the phase noise is clearly needed. Therefore, we will define the weighting functions deduced from (17) (as given by Stott for OFDM [4] and [7] for MCCDMA) for a Gaussian channel by

$$
\begin{aligned}
& W_{1}(f)=\frac{1}{N_{F}} \sum_{p=0}^{N_{F}-1 N_{F}-1} \sum_{\substack{n=0 \\
n \neq p}}\left|\psi_{N}\left(\frac{p-n}{N}-f\right)\right|^{2} \\
& W_{2}(f)=\frac{1}{N_{F}} \sum_{\substack{s=0 \\
s \neq 1}}^{S-1} \sum_{p=0}^{N_{F}-1 N_{F}-1} \sum_{n=0}\left|\psi_{N}\left(\frac{(w-s) N_{F}+p-n}{N}-f\right)\right|^{2}
\end{aligned}
$$

Where $W_{1}(f)$ represents the effect of ICI within the $w^{\text {th }}$ sub band and $\mathrm{W}_{2}(\mathrm{f})$ represents the effect of IBI on the $\mathrm{w}^{\text {th }}$ sub band. We can verify that (18) can be written as

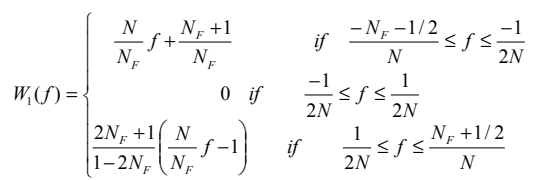

$$
\begin{aligned}
& W_{2}(f)=\left\{\begin{array}{ccc}
\frac{2 N_{F}+1}{2 N_{F}-1}\left(\frac{N}{N_{F}} f+1\right) & \text { if } \frac{-S N_{F}}{N} \leq f \leq \frac{-(S-1) N_{F}-1 / 2}{N} \\
1 \quad & \text { if } \quad \frac{-(S-1) N_{F}-1 / 2}{N} \leq f \leq \frac{-2 N_{F}+1}{2 N} \\
\frac{2 N_{F}+1}{1-2 N_{F}} \frac{N}{N_{F}} f & \text { if } \frac{-2 N_{F}+1}{2 N} \leq f \leq \frac{-1}{2 N} \\
0 & \text { if } \quad \frac{-1}{2 N} \leq f \leq \frac{1}{2 N} \\
\frac{2 N_{F}+1}{2 N_{F}-1} \frac{N}{N_{F}} f & \text { if } \quad \frac{1}{2 N} \leq f \leq \frac{N_{F}-1 / 2}{N} \\
1 & \text { if } & \frac{N_{F}-1 / 2}{N} \leq f \leq \frac{(S-1) N_{F}+1 / 2}{N} \\
\frac{2 N_{F}+1}{1-2 N_{F}}\left(\frac{N}{N_{F}} f+S\right) & \text { if } & \frac{(S-1) N_{F}+1 / 2}{N} \leq f \leq \frac{S N_{F}+1 / 2}{N}
\end{array}\right.
\end{aligned}
$$

With these assumptions, the interference power in (17) can be written for a Gaussian channel as:

$$
I[w]=\frac{\alpha \bar{P}}{(1+\gamma)^{2}} \int_{-1 / 2}^{1 / 2} S(f) W_{1}(f) d f+\frac{\alpha \bar{P}}{(1+\gamma)^{2}} \int_{-1 / 2}^{1 / 2} S(f) W_{2}(f) d f+\frac{\sigma^{2}}{(1+\gamma)^{2}}
$$

Where the first term indicates the ICI interference within the band $\mathrm{w}$, the second term indicates the IBI and the third term is the AWGN. The weighting functions given in Figure 3 and Figure 4 versus the normalized frequency f (to sub-carrier spacing) combined with equation (20) are of great help in visualizing the impact of the filtered phase noise on the studied sub band. Figure 3 shows that the low frequency components of the phase noise PSD have more impact on the
ICI however, Figure 4 shows that all frequency components of the phase noise PSD have an equivalent impact on the IBI. Thus, to discard the phase noise effect, the engineer designers have to chose PLL filters with higher cut-off frequency. Moreover, a PLL cut-off frequency greater than the subcarrier spacing will eliminate definitively the ICI while the IBI obstinately persists.

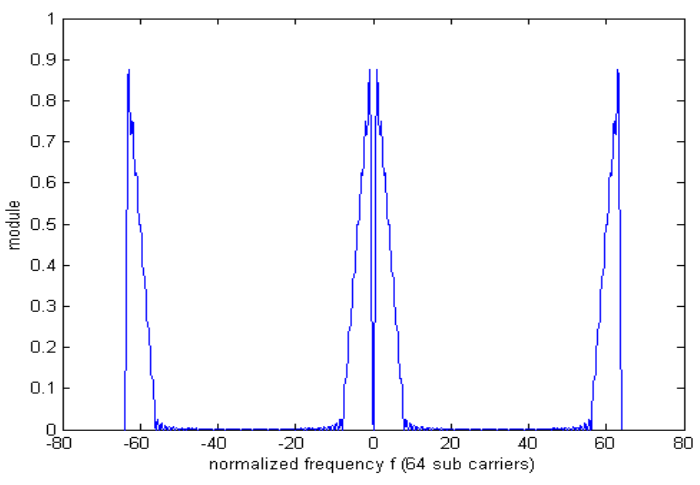

Figure 3: weighting function $\mathrm{W}_{1}(\mathrm{f})$

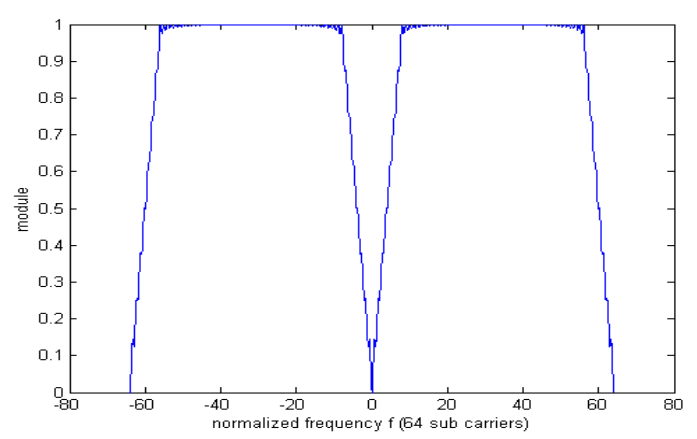

Figure 4: weighting function $\mathrm{W}_{2}(\mathrm{f})$

\section{SYSTEM PERFORMANCE}

In this section, we will validate our theoretical model given previously by means of simulations. We first compare the SINR computed with (11) and (17) with the instantaneous SINR measured via Monte Carlo simulations. However, for a frequency selective slow fading physical channel and due to the variations of the channel caused by the mobile speed, we give the comparison between the average SINRs. The simulations assumptions in the sequel are the followings:

- FFT size: $\mathrm{N}=64$, Spreading factor: $\mathrm{N}_{\mathrm{c}}=32$ chips, QPSK modulation, sub-carrier spacing $=312.5 \mathrm{KHz}$.

- Scrambling code: concatenation of 19 Gold codes of 128 chips each.

- $\quad$ Spreading schemes: MC-CDMA: $\left(\mathrm{N}_{\mathrm{F}}=32\right.$, $\left.\mathrm{N}_{\mathrm{T}}=1\right)$, OFDM-CDMA: $\left(\mathrm{N}_{\mathrm{F}}=8, \mathrm{~N}_{\mathrm{T}}=4\right)$, MC-DSCDMA: $\left(\mathrm{N}_{\mathrm{F}}=1, \mathrm{~N}_{\mathrm{T}}=32\right)$.

- PLL filter (CutOff=100KHz): $b=[0.9770-1.9541$ 0.9770] and $\mathrm{a}=\left[\begin{array}{lll}1 & -1.9881 & 0.9882\end{array}\right]$.

- PLL filter (CutOff=1MHz): $b=\left[\begin{array}{lll}0.9256 & -1.8509\end{array}\right.$ $0.9256]$ and $\mathrm{a}=\left[\begin{array}{lll}1 & -1.8790 & 0.8876\end{array}\right]$.

Figure 5 illustrates the comparison between theoretical and simulated average SINRs for BRAN A channel [20], a mean ratio $\mathrm{E}_{\mathrm{b}} / \mathrm{N}_{0}=20 \mathrm{~dB}$ and a PLL cutoff frequency of $1 \mathrm{MHz}$. The SINRs have been measured in the first sub-band $(\mathrm{w}=0)$. Figure 5 shows that our theoretical model matches 
perfectly with simulations, even for a relatively small spreading factor $\left(\mathrm{N}_{\mathrm{c}}=32\right)$. Moreover, it shows that the SINR sensitivity to phase noise becomes noticeable for a diffusion factor $\mathrm{D}>1 \mathrm{KHz}$.

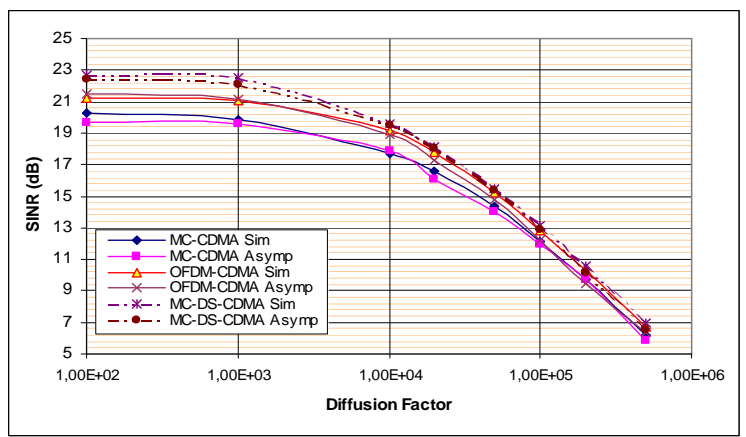

Figure 5- validation of theoretical model (BRAN A).

Since the theoretical model has been validated, we will exploit equation (17) to give more insights of the phase noise. Thus, we define the instantaneous degradation by $D e g_{(d B)}=10 \times \log _{10}\left(\frac{\operatorname{SINR}_{\max }}{\operatorname{SINR}}\right)$ where $\mathrm{SINR}_{\max }$ is the SINR obtained for a perfectly synchronized system.

Figure 6 and Figure 7 give the comparison between degradations of different spreading schemes to carrier phase noise for a BranA channel model, a mean ratio $\mathrm{E}_{\mathrm{b}} / \mathrm{N}_{0}=20 \mathrm{~dB}$, a full load and a quarter load respectively. It is easy to conclude that the sensitivity of the 3 spreading schemes to phase noise is similar. Moreover, the degradation increases with system load and decreases with the PLL cut off frequency.

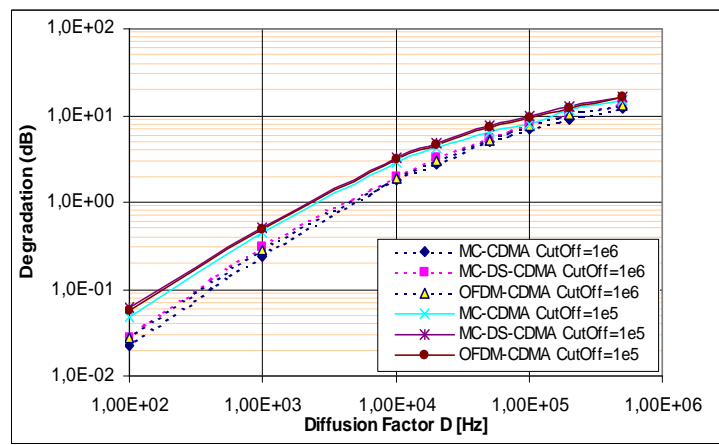

Figure 6: comparison between degradation of different spreading schemes

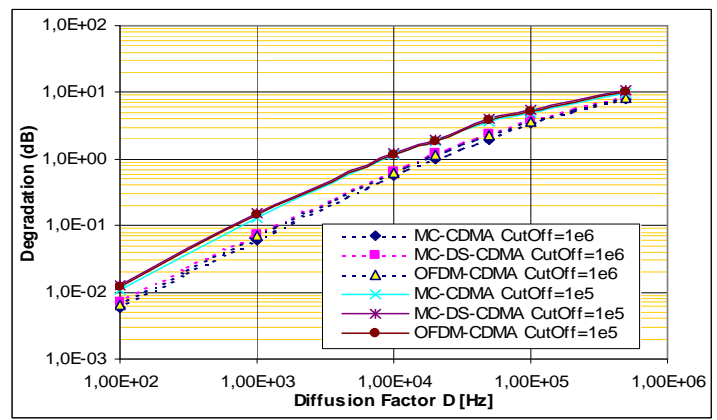

Figure 7: comparison between degradation of different spreading schemes

\section{CONCLUSION}

In this article, we have investigated the effect of the phase noise on the performance of 2D OFDM-CDMA spreading schemes. We have determined an analytical expression of the SINR which is independent of the spreading codes and showed that its results are conformed to Monte Carlo simulations. Also, we presented helpfully weighting functions used by the RF engineer to design efficient frequency synthesizers (a PLL with higher cutoff frequency is more efficient) and showed that MC-CDMA, OFDM-CDMA and MC-DS-CDMA spreading schemes are identically sensitive to the phase noise.

\section{REFERENCES}

[1] N. Maeda, Y. Kishiyama, H. Atarashi, M. Sawahashi, "Variable Spreading Factor OFCDM with Two Dimensional Spreading that Prioritizes Time domain Spreading for Forward Link Broadband Wireless Access", Proc. of VTC spring 2003, April 2003, Jeju, Korea.

[2] A. Persson, T. Ottosson, E. Ström, "Time-Frequency Localized CDMA for Downlink Multi-Carrier Systems", IEEE $7^{\text {th }}$ Int. Symp. On Spread-Spectrum Tech. \& Appl., pp. 118-122., Prague, Czech Republic, Sept 2-5, 2002.

[3] T. Pollet, M. Moeneclaey, "BER sensitivity of OFDM systems to carrier frequency offset and wiener phase noise", IEEE. Trans. On Communications, Vol.: 43, Issue 234 Feb./March/Apr. 1995.

[4] J. Stott, "The effects of phase noise in COFDM", EBU technical Review- Summer 1998.

[5] A. Armada, "Understanding the effects of phase noise in Orthogonal Frequency Division Multiplexing OFDM", IEEE Trans. On Braodcasting, Vol. 47, No.2, June 2001

[6] H. Steendam and M. Moeneclaey," The effect of carrier Phase jitter on MC-CDMA performance", IEEE Trans. On Communications, Vol. 47, No. 2, Feb. 1999.

[7] C. Dehos, M. des Noes, , D. Morche, "Sensitivity of MC-CDMA systems to carrier phase noise: a large system analysis", proceedings of PIMRC, Berlin Germany, Sept. 11-15, 2005

[8] Y. Nasser, M. des Noes, L. Ros, G. Jourdain, "SINR estimation of OFDM-CDMA systems with constant timing offset: a large system analysis", proceedings of PIMRC Berlin Germany, Sept., 11-15, 2005

[9] Y. Nasser, M. des Noes, L. Ros, G. Jourdain, "The effect of clock frequency offset on OFDM-CDMA systems performance", Symposium on Communications and Vehicular Technology SCVT, Nov. 2005, the Netherlands.

[10] Y. Nasser, M. des Noes, L. Ros, G. Jourdain, "Sensitivity of OFDM$\mathrm{CDMa}$ to carrier frequency offset", International Conference on Communications ICC 2006, June 2006, Istanbul Turkey.

[11] A. Mehrotra, "Noise Analysis of phase locked loops", IEEE Trans. On Circuits and systems Vol. 49., No. 9, Sept. 2002

[12] A. Mehrotra, "Simulation and modelling techniques for noise in radio frequency integrated circuits", PhD. Dissertation, Univ. California, Berkeley, 1999.

[13] N. Yee, JP. Linnartz, G. Fetteweis, "Multi-Carrier CDMA in Indoors wireless radio networks", proceeding PIMRC' 93 Yokohama Japan, pp:109-113

[14] A. Chouly, A. Brajal, S. jourdan, "Orthogonal multi carrier techniques applied to direct sequence spread spectrum CDMA systems", Globecom conference, Nov-Dec 1993 Vol. 3, pp.:1723-1728 USA

[15] P. Jallon, M. des Noes, D. Ktenas, J.-M. Brossier, "Asymptotic analysis of the multiuser MMSE receiver for the downlink of a MCCDMA system", Vehicular Technology Conference, 2003. The 57th IEEE Semiannual, Vol.1, 22-25 April 2003 pp. 363 - 367

[16] J.M. Chaufray, W. Hachem, Ph. Loubaton, "Asymptotical Analysis of Optimum and Sub-Optimum CDMA Downlink MMSE Receivers", Information Theory, IEEE Transactions on , Vol: 50, Issue: 11, Nov. 2004 pp:2620 - 2638.

[17] M. Debbah, W. Hachem, P. Loubaton, M. de Courville, "MMSE analysis of Certain Large Isometric Random Precoded Systems", IEEE Trans. on Information theory, vol. 43, May, No. 5 - 2003.

[18] J. Evans, D.N.C Tse, "Large system performance of linear multiuser receivers in multipath fading channels", Information Theory, IEEE Transactions on, Vol. 46, Issue: 6, pp. 2059-2078, Sept. 2000

[19] W.Hachem, "simple polynomials for CDMA downlink transmissions on frequency selectyive channels", Information Theory, IEEE Transactions on, Volume: 50, Issue: 1, Jan. 2004 pp: $164-171$

[20] J. Medbo, H. Andersson, P. Schramm, H. Asplund, " Channel models for HIPERLAN/2 in different indoor scenarios“, COST 259, TD98, Bradford,April 1998 